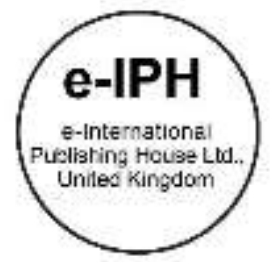

\title{
Understanding the Value of Green Event: A Case Study of Event's Company
}

\author{
Norol Hamiza Zamzuri'1, Anthony Wong², Zulkiflee Abd Latif ${ }^{3}$ \\ ${ }^{1}$ Faculty of Business Management, Universiti Teknologi MARA Selangor, Puncak Alam Campus, 42300 Puncak Alam, Selangor DE, \\ ${ }^{2}$ AOS Conventions and Events Sdn. Bhd. 39 \& 40 Jalan Mamanda 9, Ampang Point Ampang, 68000 Kuala Lumpur Malaysia, \\ 3Institute for Biodiversity and Sustainable Development, Universiti Teknologi MARA, Shah Alam, 40450 Selangor. \\ norol@uitm.edu.my, 2anthony@frangipanilangkawi.com, 32Zulki7211@uitm.edu.my \\ Tel of 1st Author: +0173707893
}

\begin{abstract}
This paper attempts to bring forward the idea of organizing a green event. A case study was conducted at AOS Convention and Events Sdn. Bhd. which is one of event's company in Kuala Lumpur. Based on active participative observation and semi-structure interview it found that AOS Convention and Events Sdn. Bhd. is very committed to practice green during an event. It also found that the event's attendees who attended the event were very satisfied with the organizing of event by the event's organizer. Future researcher is suggested to explore more on the value of organizing a green event. Keywords: Green event; Salue; Sustainable event

eISSN: 2398-4287@ 2021. The Authors. Published for AMER ABRA cE-Bs by e-International Publishing House, Ltd., UK. This is an open access article under the CC BYNC-ND license (http://creativecommons.org/licenses/by-nc-nd/4.0/). Peer-review under responsibility of AMER (Association of Malaysian Environment-Behaviour Researchers), ABRA (Association of Behavioural Researchers on Asians/Africans/Arabians) and CE-Bs (Centre for Environment-Behaviour Studies), Faculty of Architecture, Planning \& Surveying, Universiti Teknologi MARA, Malaysia.

DOI: https://doi.org/10.21834/ebpj.v6iSI4.2920
\end{abstract}

\subsection{Introduction}

This article discusses organising a sustainable business event at one of the event's companies in Malaysia. For the past few years, this company has organised several events. Hence, as mentioned earlier, this study explores the processes involved, as this company is well known for its 'green practices' while organising a business event. Therefore, I have summarised the findings in four sub-sections using interview and video interview methods to analyse the data. The first sub-section explains the meaning of a 'green event'. The second sub-section discusses the sustainable practices involved during the process and the third sub-section discusses the survey and the video interview report. Lastly, I end the discussion by summarising all the findings according to the method employed.

\subsection{Literature Review}

Implementing the green policy or its elements during an event is known as a green event (Laing \& Frost, 2010). For the past few years, authors have used several terms such as sustainability, corporate social responsibility, and green event (Laing \& Frost, 2010; Mair \& Jago, 2010). Recently, there were debates among researchers on the extent to which an event can be called a green or sustainable event (Laing \& Frost, 2010, Dickson \& Arcodia, 2010; Laing \& Frost, 2010) of the reasons was because each organiser had considered his event to be a green event. However, the extent of the sustainable practice during the process is comparatively different from one another (Laing \& Frost, 2010). The results in determining to what extent an event can be called a green event.

This leads to the aim of this study, which is to explore the process of organising a green event by AOS Conventions and Events Sdn. Bhd. The main reason this company was chosen as a case study is that for the past few years, this company has organised

eISSN: 2398-4287C 2021. The Authors. Published for AMER ABRA cE-Bs by e-International Publishing House, Ltd., UK. This is an open access article under the CC BYNC-ND license (http://creativecommons.org/licenses/by-nc-nd/4.0/). Peer-review under responsibility of AMER (Association of Malaysian Environment-Behaviour Researchers), ABRA (Association of Behavioural Researchers on Asians/Africans/Arabians) and cE-Bs (Centre for Environment-Behaviour Studies), Faculty of Architecture, Planning \& Surveying, Universiti Teknologi MARA, Malaysia.

DOI: https://doi.org/10.21834/ebpj.v6iSI4.2920 
numerous events that included green practices during the process and based on observations, I found that the green practices were not only during the event but rather this company had applied green practices throughout the whole event.

Before I discuss further on the green practices at AOS Convention and Events Sdn. Bhd., I would like to further discuss the meaning of green practices, according to several authors.

\subsection{The practice of sustainability or green practices during an event.}

Organising a sustainable or green business event is one of the strategies in applying the sustainability concept in the event industry. Sustainability is alternatively known as 'green' (Han, Hsu, \& Lee, 2009), and as mentioned earlier, the green practice is defined by Laing and Frost (2010) as the application of sustainability policies or practices during an event. It seems that organising a sustainable business event is one of the strategies for achieving sustainability goals.

Sustainability has emerged as a topic of discussion in event management, and this term is associated with economic, social and environmental issues. This is argued by Raj et al., (2010), Raj and Musgrave (2009), where according to these authors, balancing growth among the economic, social and environmental aspects is a complex and plural concept. The need for sustainable management is based on the demand stemming from industrialisation and its impact on the environment. The relationship between the growth in the economic, social and environmental aspects is described as the three pillars of impact in event management.

I refer to Raj and Musgrave's (2010) description of the three important pillars in event management as the framework proposed by both authors as being the three important elements in sustainability. The social dimension must go hand in hand with the economic and environmental dimensions. This is because, without a stable economy to support the infrastructure, sustainability in the community is hardly achieved. The community's environmental commitment to sustainable practice is to ensure that the infrastructure development will not create a negative impact on the community. This issue is highlighted by Tassioupulus (2010, p.210), and according to him, 'the core elements of social sustainability is the societal safety, the development of social resources, equity in terms of access to resources and opportunities, participation in decision making processes and investments in social capital. The author also highlighted that society is socially differentiated and not homogeneous. Therefore, organising an event is challenging as it involves various effects on individuals and groups within a community. Both factors imply that event organisers need to understand the range of social impact towards individuals and groups within a community. Apart from the social issue, this author also emphasised the economic considerations, especially for developing countries such as South Africa, Brazil and India.

The author stressed that 'it is crucial for event stakeholders and managers to develop economic development strategies that do not create a negative economic impact such as economic leakages, price hikes, increase in taxes and limited economic opportunities for the community' (p. 214). For this reason, several economic assessments were applied to assist in monitoring economic performance. The economic performance is evaluated through tourist expenditure during the event and while at the destination, the sponsorship contribution for the event and capital expenditure on infrastructure, jobs created by the event and government taxes or revenues generated from the event. The last issue highlighted by Tassioupulus (2010) is the environmental issue. The author stressed that 'greening of an event refers to the growing importance of incorporating environmental issues in event planning and implementation' ( $p$. 217). Hence, for this reason, it appears that three important issues are highlighted by these authors, namely social, economic and environmental. Therefore, it seems that a sustainable event should consider the social, economic and environmental elements during event activities. However, in this discussion, I will only discuss sustainable or green practices as one of the strategies in achieving sustainable performance because there is a chance of a potentially negative environmental impact if the activities are not managed well by the event organisers. The business event involves utilising several event materials such as paper, polystyrene, plastics and energy. However, these materials and energy can produce a negative environmental impact if it is not managed well. Therefore, it is important to monitor the process of greening a business event.

In this study, the environmental performance is evaluated through waste, water and energy consumption. As mentioned earlier, there is a potential for a negative impact from the growth of this sector on the environment. The impact indicates the importance of adopting the sustainability concept in an event. However, the sustainability concept in an event demands full commitment from all event stakeholders. The commitment among event stakeholders, such as convention venue providers, in practising sustainability becomes an added-value feature for the event business. The commitment among convention venue operators towards sustainable practices can be observed, for example, in the involvement of the Kuala Lumpur Convention Centre in the "EarthCheck" benchmarking program.

An event depends on the audience, the host community and the event organisers (Golblatt, 2010). Therefore, it seems that greening an event depends on the event organisers and the audience. The challenge faced by event organisers is to find common ground between event activities (Tassiopoulus, 2010). Therefore, in this study, the green performance is evaluated based on the attendee's satisfaction when attending an event and the practices of event organisers throughout organising an event.

\subsection{Methodology}

The researchers began the actual fieldwork with an event company as it permitted the involvement of participatory observation. For this reason, the study further explored semi-structured interviews with ten event's attendees who play a role as event's attendees. The member check and interview protocols were also used in validating the information. An analysis of in-depth interviews with several event practitioners provided extensive and in-depth information on these issues. The information obtained through analysis has formed a link through the development of several themes. The themes then provided a link to the meaning, process and factors involved in organising a sustainable business event. 


\subsection{Findings}

Based on the survey, it was revealed that 54.3 per cent of event attendees attended the event for their personal development. This is highlighted from one of the video interviews with event attendees. This is stated as:

"Is very great event, I find most of the sessions are very interesting. I learn a lot and very impress with your prime minister's speeches and the presentation from John Kerry; I find it very2 inspiring and very motivational. An event like this may change our lives forever, and it is great".. (Interview 3)

This is also mentioned by one of the delegates from Tanzania.

"This is a wonderful place to be, a nice place to talk and wonderful place to be, a wonderful place to talk and the place to exchange ideas and also place whereby we can find future collaboration, future work, help entrepreneur to grow as a whole and build small and medium enterprise an around the globe and our country also. The session is very interesting". (Interview 7)

This is supported by

"The event is very enriching and is a motivation platform for me as well as listening to a speaker who has done it and is there, is something encouraging. Overall a very moving is very great for me". (Interview 10).

Based on the above discussions, it shows that attending the event is for personal development because they feel that the event provides a platform for them to meet people from all over the world. This event enables them to meet other delegates and the speakers of the event, who provided them with fruitful ideas and comments. Based on the speaker's presentation, this event has also motivated them towards the future enhancement of their career.

Apart from attending the event for personal development, the survey also reported that 84.6 per cent of the event attendees feel that the event is essential. This is mentioned as:

"I find to be extremely lightening one we have a lot encourages people, people who look failure of ways for success and most important people who dare to look beyond and look towards the future where we realise the answer is not revealed but beyond that yes-one of the most ambitious gatherings from a lot of minded Malaysian and oversea. I fun met many people and see a lot of technology". (Interview 12)

This is also stated as:

"Ya!! It is a great event; we came here to see the entrepreneurship environment in Malaysia and worldwide. It is very significant to see every experience, very knowledgeable people sharing their experience.

We learn a lot, so many things here.

The speaker is amazing, people ask challenging, but they handle it very well.

The delegates networking is very good, and I exchange my business card with them. I met many friends with excellent networking opportunities. I find other people from other sectors, and we share our experience; it was a great networking experience".

(Interview 14).

It shows that the event is important to the delegates as it provides the opportunity for them to share ideas and develop networking with other delegates.

Also reported from the survey was that 87.6 per cent said that the event departed much knowledge to them, 95.5 per cent stated that the event provided them with a networking opportunity, and lastly, 95 per cent of the event attendees were satisfied with the overall event.

In terms of the event venue, 86.5 per cent of the event attendees felt that the event venue was perfect. This is mentioned by $x x$ :

"The venue is excellent for everybody and so is the accommodation. I do not have the experience of attending an event where they serve coffee at the end of the session. Great food, and I liked the coffee right away, available first time in Malaysia.

This is also mentioned by Interview 14

"The venue is amazing, and this convention centre is amazing, gorgeous and perfect". (Interview 14)

This is supported as:

"The venue is very nice, very well organised, lunch is provided. Basically it is very awesome". (Interview 9).

The delegates were also impressed with the performance of the event organisers. This is mentioned by Interviewee 5 . "Lets me see, yes, the event size is really big, that means that it is awesome to be here".

This is supported by Interviewee 9.

"The event is well organised".

It was reported from the survey that 81.4 per cent found that the service provided by the event organisers was very good. In addition, 72.7 per cent found that the exhibition was fascinating, while 67.9 per cent of the delegates agreed that the CSR program was good. It is also mentioned from the interview that the delegates were interested in attending the event again.

Based on the discussion regarding event attendee satisfaction, it appears that the delegates were delighted with the event and intended to attend the event again in the future. They also feel that the event provides fruitful information and a chance for them to move ahead as this event provides the opportunity for them to form new businesses and meet new people. The venue chosen for this event is very conducive as it is located in the middle of Kuala Lumpur city and the service provided by the hotel was satisfactory. The delegates consider knowledge, networking and social elements essential factors that influenced them to attend the summit.

\subsection{The green practices of AOS Convention and Events}

\subsubsection{The utilisation of energy}


Based on the report, it appears that there is an increase in energy usage for October. One of the reasons is that the event took place in October; therefore, it seems that energy use was higher for this month. However, in reducing the use of energy in this company, the AOS Convention and Events Sdn. Bhd practices several energy-saving practices during its business operations.

Below are the lists of green practices for energy savvy Controllable Aircond

- $\quad$ Controlling the use of lighting during lunch.

- $\quad$ The use of 1 pendaflour bulb instead of 2 .

- The use of stainless steel cups for a drink.

Apart from the above, this company is implementing the rainwater box for use in the company's toilets.

\subsubsection{Water}

The volume of water usage shows that there is an average volume of water usage. One of the reasons, based on the interview with one of the employees at AOS Conventions and Events Sdn. Bhd. was that the company practices green by creating awareness among employees on the usage of water.

This is stated by one of the employees.

"The top management asked us to control the use of water, and they always advise us to practice green in this office".

Apart from creating awareness on the practice of green to the employees, AOS Conventions and Events Sdn. Bhd. also practices green by recycling the wastewater produced in the arcade as toiletry wash water.

\subsubsection{Waste}

One of the waste products that were produced during the event was the event vertical posters or buntings. The AOS Conventions and Events Sdn. Bhd. practices green during their events by recycling the unused vertical posters or buntings through Biji-biji Initiative, which is a company that assists Yayasan Innovation Malaysia and GOLD Foundation in designing a conference bag. This is illustrated at photo 1.

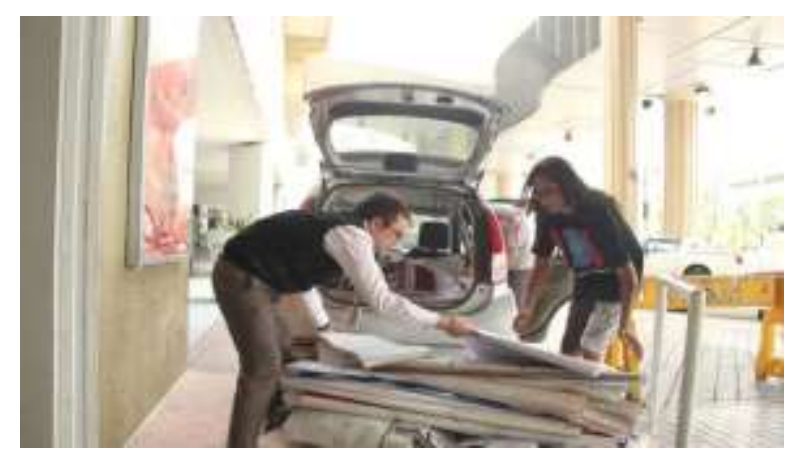

Photo 1: From AOS Convention and Events Sdn. Bhd. to GOLD Foundation Centre and the process of making conference bags at GOLD Foundation Centre.

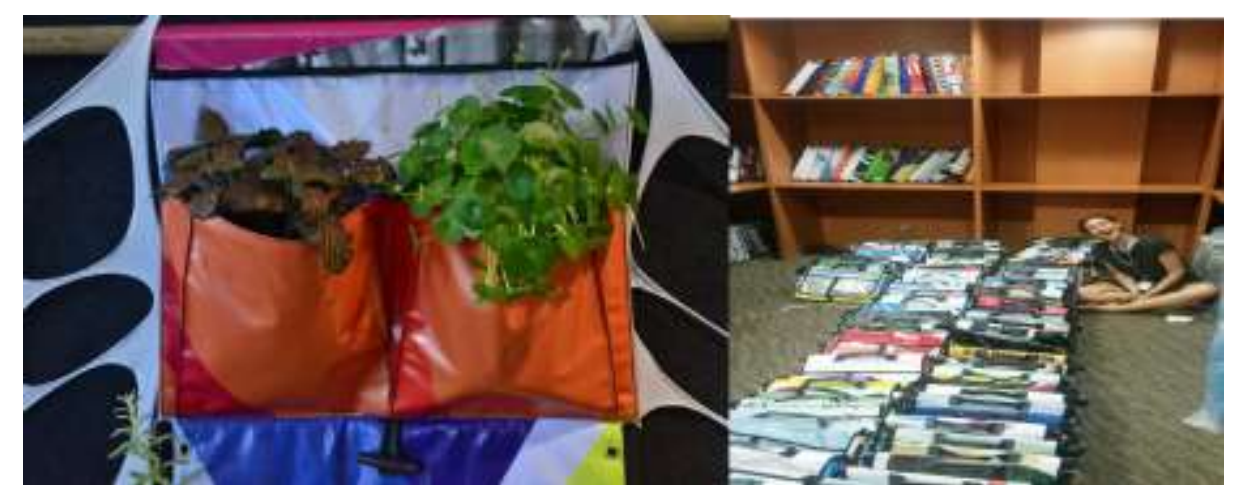

Photo 2: The unused buntings are ready for IGEM 2013 conference bags and decoration during business events.

There were 1888 square meters or the equivalent of 10 tennis courts of unused vertical posters or buntings from the business collected by the Biji-biji Initiative. In producing bags from the new buntings, the Biji-biji initiative appoints GOLD Foundation, an NGO association, to do the fieldwork (Refer Photo 2). The vertical posters are recycled into souvenir gift bags for the next coming conference. The conference was held in December 2013 and used the recycled vertical buntings as conference bags for their delegates. Refer Photo 3. 


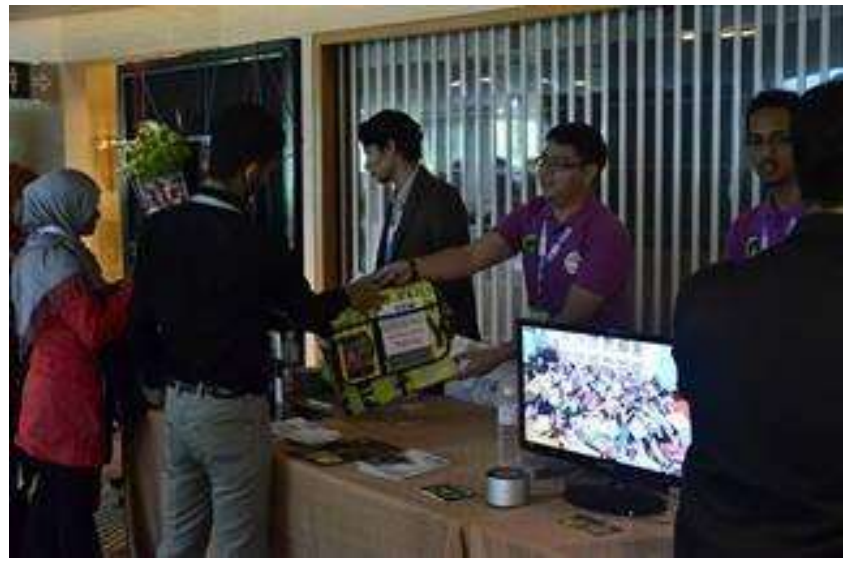

Photo 3: The conference bag that was made from unused buntings was distributed during business event delegates.

\subsection{Corporate Social Responsibility Program}

Based on observation during the event, it appears that there is a Corporate Social Responsibility Program practised by the AOS Convention and Events Sdn. Bhd. The Corporate Social Responsibility practices are as below:

\subsubsection{Recycle Box}

During the event, a recycled box prepared by the organiser was placed at one of the sections at the Conference Hall. Based on the observation, several items collected by the organisers were namely bags, pens and paper.

\subsubsection{The Lets and Meets Program as a Green Campaign}

This campaign is one of the strategies of the Ministry of Tourism and Culture in Malaysia for creating awareness among the community in practising green during an event. The delegates are encouraged to donate a minimum of USD 10 as a donation. The amount collected is used for tree planting programs. At the end of the three-day event, the amount collected was RM570.

\subsection{Discussion}

The AOS Conventions and Events Sdn. Bhd. successfully practised the CSR program. The practices showed that the company is committed to practice green during their business activities. The event is a platform for increasing knowledge and networking. This event generates new ideas for the delegates, especially the youth. The GES 2013 event is an event that practices green as a whole. This is seen from the practices by the event organiser, namely the AOS Convention and Events Sdn. Bhd in practising green before, during and after the event. The company's commitment is observed from several green practices and support from top management to the employees in emphasising green during business operations. Therefore, it is concluded that the AOS Conventions and Events Sdn. Bhd is committed to achieving green credentials.

\subsection{Conclusion \& Recommendations}

In conclusion, green event value is seen as in demand for emphasising sustainable concepts in event management. Although there is still a lack of awareness among the event's organiser on how to organise a green event, yet the effort from the event's organisers is significant in achieving sustainable development goals. In achieving the sustainable goal, several areas are in demand for the researcher to highlight, especially the un-captured value from the process of organising a green event.

Un-captured value is not only highlighted in the use of materials but also in community engagement throughout the process of organising the event. This shows that un-captured value is not only seen from the use of the event's materials, but the value is also on the community commitment throughout the event. However, there are still much to be explored on the un-captured value, such as emotional commitment.

\section{Acknowledgements}

Acknowledgements and Reference heading should be left justified, bold, with the first letter capitalised but have no numbers. Text below continues as normal. 


\section{References}

Dickson, C., \& Arcodia, C. (2010). Promoting sustainable event practice: The role of professional associations. International Journal of Hospitality Management, 29(2), 236- 244. https://doi.org/10.1016/j.jhm.2009.10.013

Han, H., Hsu, L. J., \& Lee, J. (2009). International Journal of Hospitality Management Empirical investigation of the roles of attitudes toward green behaviors , overall image, gender, and age in hotel customers ' eco-friendly decision-making process. 28, 519- 528. https://doi.org/10.1016/j.ijhm.2009.02.004

Laing, J., \& Frost, W. (2010). International Journal of Hospitality Management How green was my festival : Exploring challenges and opportunities associated with staging green events. 29, 261-267. https://doi.org/10.1016/j.jijhm.2009.10.009

Mair, J., \& Jago, L. (2010). The development of a conceptual model of greening in the business events tourism sector. 18(1), 77-94.

https://doi.org/10.1080/09669580903291007

Raj, R., Cabi, J. M., \& Robson, L. M. (2010). Event Management and Sustainability Sex Tourism in Africa : Kenya 's Booming Industry. Annals of Tourism Research, 37(4), 1200-1201. https://doi.org/10.1016/j.annals.2010.07.006

Tassiopoulus, D. (2010). Event Management: A Developmental and Managerial Approach

Claremont: Juta. 